\title{
Study of the Mix Cement Properties of Mortar Cement Used in Masonry and Plaster from the Waste Biscuit Firing of Ceramic
}

\author{
Wiwat Klangvijit ${ }^{1}$ and Krissadang Sookramoon ${ }^{2}$ \\ ${ }^{1}$ Department of Electronic Communication and Computer Technology, Faculty of Industrial Technology Vallaya Alongkorn Rajabhat \\ University 1 Moo 20 Tambol Klongnueng Amphoe Klongluang PathumThani, Thailand \\ ${ }^{2}$ Department of Mechanical Engineering Technology, Faculty of Industrial Technology Vallaya Alongkorn Rajabhat University \\ 1 Moo 20 Tambol Klongnueng Amphoe Klongluang PathumThani, Thailand
}

\begin{abstract}
The purpose of this study is to study the characteristics of cement mixes and to find out the right qualities according to Mortar Cement in terms of flow formation period and compressive strength. This work was tested for the properties of cement Mortar at Research and Development Department, Department of Concrete Testing, Royal Irrigation Thailand in ASATM C 91-97C, and ASTM C 807-89 standard. The results of the study indicated that the formula of Mortar Cement A1 flow characteristics 112, the formation time was 45 minutes and the compression strength was on the average of $39.35 \mathrm{MPa}$. Mortar Cement A2 flow characteristics 112 formation time was 45 minutes, compression strength was on the average of $25.35 \mathrm{MPa}$. Mortar Cement A3 properties of flow 118, formation time was 60 minutes, Compression strength was on the average of $17.73 \mathrm{MPa}$. Mortar Cement A4 features of flow 113, formation time was 55 minutes, compression strength was on the average of $15.33 \mathrm{MPa}$. Mortar cement A5 features of the flow 114, formation time was 55 minutes compression strength was on the average of $15.30 \mathrm{MPa}$. From the experimental result, we found that the best formulation is Mortar Cement A1, which has the highest characteristics in every property. From this study Molar cement, a material in the pozzolanic group, it is suitable for production and development in repairing old buildings or historic site. Mortar Concrete has less expansion, but high density of water slow rate ofdevelopment due to slow reaction with water. However, the compressive strength in the back is the same, the old work with the repair parts do not crack because of the surface tension, the material affected by rapid dehydration.
\end{abstract}

\section{Introduction}

Mortar or "ready-mixed cement" is a mixture of cement, sand and special additives in the appropriate ratio from the factory. Just rinse the bag and add water to the proportion that you can use it. This cement has a variety of formulas. The multi purpose use such as; plastering, multi-purpose repair, floor leveling, waterproofing and bonding of concrete walls with a worthy adhesion to concrete walls, which was not slipping. The application of this material is both inside and outside wall construction, which reduce cracking in smoother walls for concrete plastering. These materials, such as; plaster surface, surface finish, cast concrete, gypsum board, fiber cement board is widely used in Thailand. Removes surface imperfections, such as; air bubbles, small cracks, cracks, sagging marks, sand marks on the plaster surface of the walls and ceilings, both inside and outside are well known as well. Benefits of using mortar are working faster; reduce the work process, instant water dispenser, and consistency weight all bags. Save labor to mix mortar, conveying materials and eliminate residues. Reduce problems to repair. In the process of producing ceramics, burning bricks, clay pot plant pottery dishes are also called low-burning products. We find that there are about 2 tons of waste in the process of production per month. Most of them will be ground into the powder and return to the low pottery to reduce the damage of the workpiece. The researchers are interested in developing, processing to add value and create new products. The researcher is interested to bring the waste from the low-pottery pottery to develop mortar. Because the chemical structure consists of aluminum oxide $\left(\mathrm{Al}_{2} \mathrm{O}_{3}\right)$, ionic oxide $\left(\mathrm{Fe}_{2} \mathrm{O}_{3}\right)$, silicon dioxide $\left(\mathrm{SiO}_{2}\right)$ and lime $\left(\mathrm{CaCO}_{3}\right)$, we will obtain a fine mortar with fine sand when water is added to the optimum ratio. There are many researches on this subject. Burachat Chatveera and Permphon Srinourn [1] studied the characteristics of Portland Cement Type 4 Mix with rice husk ash and limestone powder. The properties of Portland cement, mix with ground ash and limestone powder to find out the physical and the chemical properties that are water requirements. In the study of compressive strength and shrinkage of concrete, the solutions used in this study were sodium sulfate $\left(\mathrm{Na}_{2} \mathrm{SO}_{4}\right)$ and magnesium sulfate $\left(\mathrm{MgSO}_{4}\right)$. The concentrations of these two solutions were $5 \%$ by weight, in accordance with ASTM C1012 standard, rice husk ash and limestone powder with a particle size of 29,12 and 128 micron. 
Rice husk, ash, and limestone powder in Portland cement are $0 \%, 20 \%$ and $40 \%$ weight of cementitious materials. The ratio of water to cement material is controlled according to the water requirement. The results showed that the compressive strength of mortar was at $110 \pm 5 \%$. Decrease in percentage of rice husk ash and limestone powder. In Portland cement at the age of 180 days, the compressive strength of all concrete was lower than the control mortar (mixture of rice husk ash and limestone powder). The compressive strength is in the highest value in concrete control. As a result of the resistance to sulfate, the substitution of rice husk, ash, and limestone powder in Portland cement are in a higher percentage of concrete loss and shrinkage. Baboo Rai, Sanjay Kumar, and Kumar, Satish [2] evaluated the compressive strength and shear strength of 1: 3 sand mortar. The natural sand was replaced with $20 \%, 50 \%$ and $100 \%$ by weight of rock dust, by partial displacement $(15 \%, 20 \% 25 \%$ and $30 \%)$ of low calcium fly ash. The compression time and shear strength were determined within 3, 7, 28 and 50 days. The results showed that the use of fine powdered rock and fly ash was the most effective. Due to its ability to efficiently fill the microorganism and the pozzolanic reaction. G J Prasanna Venkatesh, S, S Vivek and G Dhinakaran [3] carried out the structure, which was used as a pillar and then plastered increase the adhesion of brick, sand, cement, adhesion. In the study of cement mortar repair, structural restoration and plastering wall technology of Mortar is necessary. Cement was replaced with minerals from $5 \%$ to $20 \%$ (up to $5 \%$ ), Metakaolin (MK) from $10 \%$ to $30 \%$ (up to $10 \%$ ) and large scale furnace slag (GGBS) from $25 \%$ to $75 \%$ (25\% increases). The ratio between cement and fine sand is 1:2 for all cement, cement and mortar components. Incubation with a different temperature was $128{ }^{\circ} \mathrm{C}$ for 4 hours. The results showed that the compressive strength of the conventional drying method and the electric oven was higher than that of the conventional concrete. The cement substitution by SF $15 \%$, MK 20\% and GGBS $25 \%$ were stronger than those of both types. The purpose of the study was; to study the mixture rate of Portland cement, waste from the low-pottery, lime, fine sand for mortar used in plastering work and to study of mortar properties in accordance with ASATM C 91-97C, ASTM C807-89 standard for example; in terms of flow, time setting, and compressive strength.

\section{Materials \& method}

Portland cement is a mixture of limestone, soil, dirt, gypsum, mined, and mixed with water to be mixed together to burn at 1000 degrees Celsius; it will be grinded black gray to grind. 320 metric tons are collected in silos. Portland cement is used to mix stone, sand and concrete water used to make foundation beams, buildings, and condominiums. Waste from the low pottery or biscuit waste from the low-voltage containers or the brick-burning plant. There will be waste from the combustion process of 2 tons per month; one part will be used to grind the soil to be mixed with new products to reduce the crack. But with chemical elements, there are aluminosilicates. Ferric Oxide Silicon oxide can be used as a mixture of mortar. When removing the waste material from the low-pressure container, and mixed with lime and Portland cement. Mortar is used in construction and plaster works. Limestone is Lime is derived from the explosion of Limestone Mountains with lime. Take the limestone to mill and find out the sieve size and put on 20 kilograms per bag. Lime is a chemical element is calcium oxide. When mixed with the ground biscuit powder and sand, it turns to be mortar. Sand originated by the erosion of sandstone in the mountains and is carried through the canal, river canals and when deposited into the belly or led into the river, so the sand sucked up and mixed with cement.

\section{Methodology}

Terms of flow testing:

1. Clean the surface of the table, flow clean and dry. Then place the flow test down in the middle.

2. Load the mortar in a flow test to a height of about 25 $\mathrm{mm}$ and protruding the ram with 20 times throughout the cut.

3. Load the mortar in another 1 layer of about $25 \mathrm{~mm}$ height and mortar as well as the first layer of the mortar to put the second layer of mortar to a higher.

4. After the ram has been completed. Trowel the surface. The steel trowel is almost perpendicular to the surface of the model.

5. Lift up slowly in the vertical direction. It takes time to put the mortar down until it is lifted from the surface of the table, about 1 minute flow.

6. After the lift out of Mortar Rotate the table of flow. This will lift the spool of the flow table up to $13 \mathrm{~mm}$ high and let loose 25 loops in 15 seconds while rotating the swivel of the flow table. Keep tables tightly closed. Do not move because it will cause erroneous test flow.

7. Mortar was put on the plate on the top of the table, the flow will be spread like a circle. Vernier caliper was used to measure four times in the center of the mortar, at a distance of 45 angles (or measured along the trailing line on the plate of the flow table) plus the reading value. 4 sessions of Calipers The reading is the percentage of the mortar diameter increased from the original (the diameter of the flow test is $10 \mathrm{~cm}$ ).

8. For testing using Portland cement. Record flow values between $110(+5,-5)$ by adjusting the amount of water used to mix. [4]

\section{Cement paste setting time testing:}

1. Cement paste is prepared and make a round ball quickly. Use the glove and then throw it - come 6 times, both hands about $15 \mathrm{~cm}$ apart.

2. Put the cement paste into the large cone by hand. Press in and then use the hand to scrape the pest to smooth at once. Then put it on the glass. With the glass plate to make the pest to overflow smoothly with the large cone edge, then use the steel girdle to pour the cement pest into the small cone smooth to the edge of the cone. The steel 
tilt is oblique and smooth. If any part of the pest cement is cracked or uneven, use a steel girdle repeatedly or gently. Do not press on the surface of this cement paste.

3 . The cement paste cube band (This cement paste must be placed on the glass all the time. Move it up with this sheet of glass.) Leave it in a damp room for 30 minutes without being disturbed or inflicted.

4. Pass the cone with the glass plate to the test stand. $1 \mathrm{~m}$ of vibration test kit Adjust the needle scale to the surface of the cement pest, then adjust the test specimen to the sink to scale $(0)$, so that the distance between the base of the base and the base of the cone is not less than $9 \mathrm{~mm}$ and the next test, the distance of the standard needle is at least $6 \mathrm{~mm}$ away from the original image tested.

5. Release the standard needle to sink in the pestle for 30 seconds and read the sink on the scale. The intensity may be bent or damaged. Because cement pest is very weak. The needle may be impacted against the glass placed underneath the cone. Then slowly release the needle into the cement pest. This method is technically only not the correct way (the correct method is to release the needle only).

6. Consent it for 15 minutes and test it again. (In accordance with clauses 4 and 5) with time recording of the penetration of the standard needle. Do this until the sinking period. $25 \mathrm{~m}$. The values are inclusive of the time from the beginning of the mixture to the duration of the $25 \mathrm{~mm}$ sink, called the initial formation period.

7. The formation of the end of this form would variate with the use of the needle to release the needle on the surface and then perform on the cement surface pest. The time from the start of the mix of this time is the end of the formation phase. The cement paste setting time testing is shown in Figure 1.

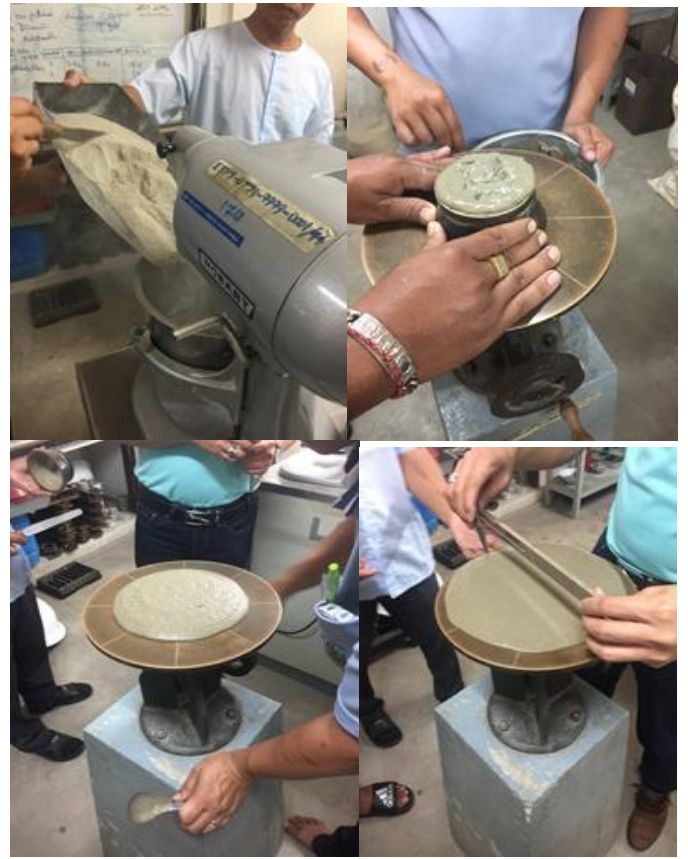

Figure 1. Cement paste setting time testing.

\section{The compressive strength testing:}

1. Cement cube mold in the size of $2 \times 2 \times 2$ inch or $50 \times 50 \times 50 \mathrm{~mm}$, the test form must be tightly packed. Up to two pieces can be used and one cast has a maximum of three cubes. The mold is made of solid material, smooth surface, with corner angle. Not more than $0.5 \mathrm{~mm}$ and not reacted with mortar. Flow Table and Flow Mold used to test the flow of mortar. Comply with ASTM Designation C-230.

2. Tamper rods must be made of non-absorbent material. It is not worn or frictionless and fragile, such as made of hard wood, then discarded. And do not absorb water by soaking in hot paraffin oil at $200{ }^{\circ} \mathrm{C}$ for 15 minutes or by hardening with a hardness of $80 \pm 10$ measured by a Shore A Durometer. The field must have a cross section of $13 \times 25 \mathrm{~mm}(1 / 2 \times 1$ inch) and a length of about 120 to $150 \mathrm{~mm}$ and the cross section shall be perpendicular to the long axis of the rod.

3. The mixer is electrically driven. Comply with ASTM designation C-305.

4. Balance is reading $0.1 \mathrm{~g}$.

5. Measuring cylinder is large enough to measure water only once. The measurement was done at $20{ }^{\circ} \mathrm{C}$ with a tolerance of not more than $\pm 2 \mathrm{~m}$. In this test, the measuring range was $500-1000 \mathrm{~m}$.

6. Trowel (flat iron) the rim of the trowel.

7. Vernier Caliper is measured in the range of 8-10 inches. 8. Hydraulic testing machine, the spiral between the front of the upper and lower keys. It must be enough space to remove the equipment needed to test the installation. And the gap for the test cube fit. Pressures must be accurate to \pm 1 percent. The upper and lower keys are hard metal. The top of the keyboard has a rounded base that fits snugly against the center of the upper key. As we walked the test machine, the top was down with the specimen on top of it, although it was firmly attached to the sphere. It can be tilted in all directions according to the surface of the contact surface of the press pad, platen plate hardened using a test sample. The Rockwell hardness must not be less than HRC 60. [5] The Compressive Strength testing is shown in Figure 2.

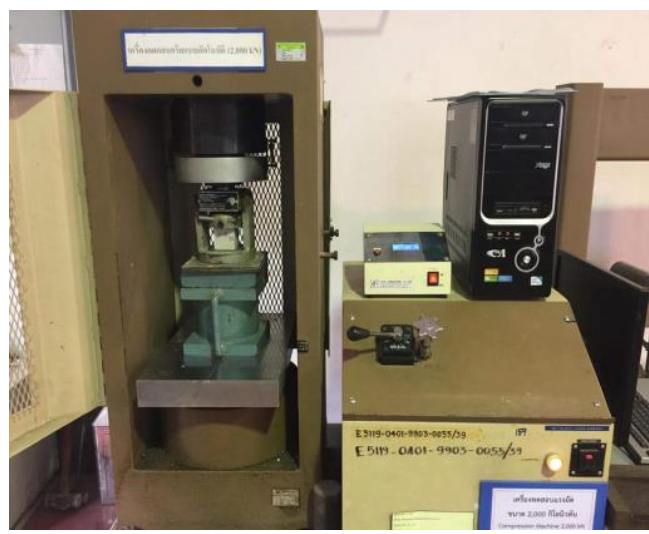

Figure 2. The compressive strength testing. 


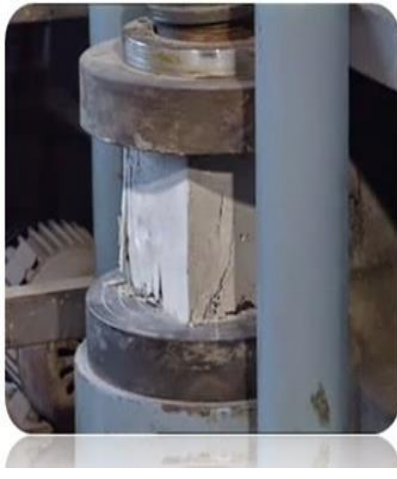

Figure 3. The compressive strength testing.

\section{Experimental results}

Table 1 shows the properties of mortar by studying the ratio of Portland cement, low-calorie, lime, fine sand which categorized in formula $\mathrm{A}_{1}-\mathrm{A}_{5}$. Terms of flow is shown in Figure 4, The cement paste setting time is shown in Figure 5, and The Compressive strength of Portland cement is shown in Figure 6. Mortar has a standard of the flow rate of $110(+5,-5)$, the formation period time is 60 minutes and a compaction capacity is 2.5 mega pascal. Formula $A_{1}$ is the best property of mortar mixing Portland cement. Formula $\mathrm{A}_{2}-\mathrm{A}_{5}$ permits the standard, excluding the formular A3 does not pass the standard because the terms of flow exceeds the regular.

Table 1. The properties of mortar by studying the ratio of Portland cement, low-calorie, lime, and fine sand which are categorized in Formula $\mathrm{A}_{1}-\mathrm{A}_{5}$.

\begin{tabular}{|l|l|l|l|l|l|l|l|}
\hline $\begin{array}{l}\text { Fom } \\
\text { ula }\end{array}$ & $\begin{array}{l}\text { Portl } \\
\text { and } \\
\text { cem } \\
\text { ent } \\
\%\end{array}$ & $\begin{array}{l}\text { Wast } \\
\text { e } \\
\text { from } \\
\text { the } \\
\text { potte } \\
\text { ry } \\
\%\end{array}$ & $\begin{array}{l}\text { Limes } \\
\text { tone } \\
\%\end{array}$ & $\begin{array}{l}\text { San } \\
\mathrm{d} \\
\%\end{array}$ & $\begin{array}{l}\text { Ter } \\
\mathrm{ms} \\
\text { of } \\
\text { flow }\end{array}$ & $\begin{array}{l}\text { Sett } \\
\text { ing } \\
\text { tim } \\
\mathrm{e} \\
\text { min } \\
\text { ute }\end{array}$ & $\begin{array}{l}\text { Mean } \\
\text { Compre } \\
\text { stive } \\
\text { Strength } \\
\text { Mpa }\end{array}$ \\
\hline $\mathrm{A}_{1}$ & $\begin{array}{l}12.1 \\
4\end{array}$ & $\begin{array}{l}15.1 \\
7\end{array}$ & 12.69 & 60 & 112 & 45 & 39.35 \\
\hline $\mathrm{A}_{2}$ & $\begin{array}{l}12.1 \\
4\end{array}$ & $\begin{array}{l}12.6 \\
9\end{array}$ & 15.17 & 60 & 112 & 45 & 25.35 \\
\hline $\mathrm{A}_{3}$ & $\begin{array}{l}13.2 \\
5\end{array}$ & $\begin{array}{l}13.5 \\
0\end{array}$ & 13.25 & 60 & 118 & 60 & 17.73 \\
\hline $\mathrm{A}_{4}$ & $\begin{array}{l}13.2 \\
5\end{array}$ & $\begin{array}{l}13.2 \\
5\end{array}$ & 13.50 & 60 & 113 & 55 & 15.33 \\
\hline $\mathrm{A}_{5}$ & $\begin{array}{l}10.9 \\
0\end{array}$ & $\begin{array}{l}18.2 \\
1\end{array}$ & 10.90 & 60 & 114 & 55 & 15.30 \\
\hline
\end{tabular}

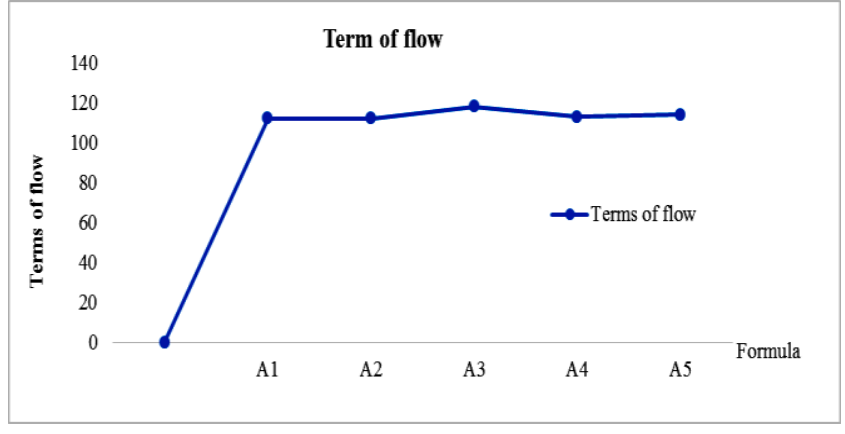

Figure 4. Term of flow of each formula.

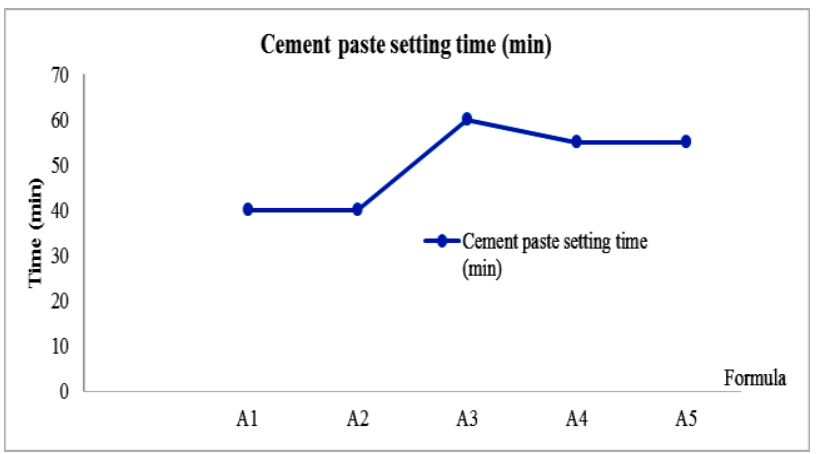

Figure 5. The cement paste setting time of each formula.

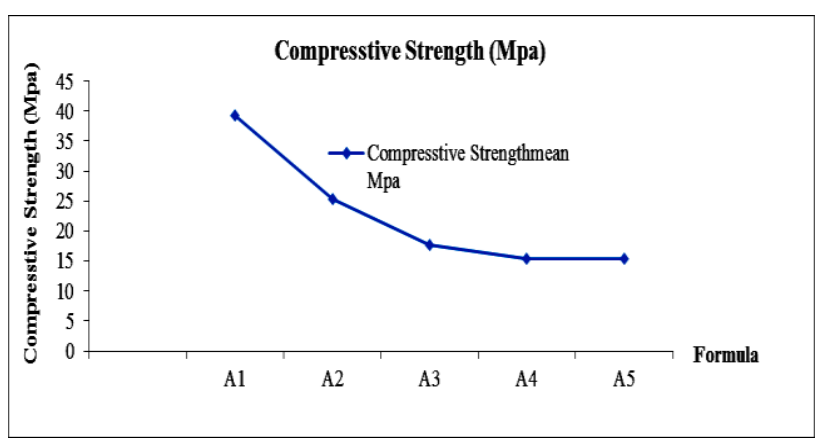

Figure 6. The Compressive strength of Portland cement of each formula.

\section{Summary}

The properties of mortar mixing Portland cement from the study(low-calorie, lime, fine sand) indicated that the best mixing ratio of Portland cement was $12.14 \%$. Waste from the low pottery was $15.17 \%$ Limestone was $12.69 \%$, and sand was $60 \%$. The high quality of the experiment was formula $A_{1}$ in terms of flow 112 and the cement paste setting time was 45 minutes and the mean compressive strength was $39.35 \mathrm{Mpa}$. Cement mixes for material Pozzolan are suitable to be used in the repair and construction of old buildings. Concrete has a less expansion high density of water. Slow rate of development due to slow reaction with water. However, the compressive strength is the same level as the old value, the old work with the repair parts do not crack because of the surface tension, the physical affected by rapid dehydration. 


\section{References}

1. Chatveera, B. and Srinourn, P. A Study of Properties of Mortar, Portland Cement Type V Mixed with Ground Rice Husk Ash and Limestone Powder. Journal of Research and Development King Mongkut's University of Technology Thonburi. Year 2 April - June (2012)

2. Baboo Rai,Sanjay Kumar,and Kumar Satish. Effect of Fly Ash on Mortar Mixes with Quarry Dust as Fine Aggregate. Hindawi Publishing Corporation Advances in Materials Science and Engineering, Volume Article ID 626425,7 pages (2014)

3. G. J Prasanna Venkatesh, S S Vivek and G Dhinakaran. Study on compressive strength of self compacting mortar cubes under normal \& electric oven curing methods. ICCIEE 2017 IOP Conf. Series: Earth and Environmental Science80 012002 (2017)

4. SIRISAWAT I, SAENGSOY W, BAINGAM L, KRAMMART P. Durability and testing of Mortar with underground fly ash and limestone cements in sulfate solutions. Journal of Construction and Building Materials, Vol.64 (2014)

5. ZHANG Ming-hua, JIANG Ming-qiang, CHEN Jian-kang. Variation of flexural strength of cement mortar attacked by sulfate ions. Journal of Engineering Fracture Mechanics, Vol.75 (17) (2008), p. 4948-4957. 